\title{
Association of Conflict Resolution Style and Relationship Satisfaction between Couples
}

\author{
Eyob Ayenew ${ }^{1 *}$
}

\section{ABSTRACT}

Background: Relationship researchers have focused on the frequency of conflict in couples' relationships and the manner in which couples engage in and try to resolve conflicts. Conflict occurs regularly in most close relationships and dealing with conflict, under some conditions, may facilitate the development and maintenance of intimacy and satisfaction in a relationship. Regardless of this understanding, very little is known about individual's characteristics of conflict resolution behavior that bring into couples relationship satisfaction. Objective: The purpose of this study is to examine individual's characteristics in conflict resolution behavior and its effect on couple relationship satisfaction. Methodology: A total of 306 (159 female and 147 male) participants were included from community sample. Three Kebeles in Yeka sub-city of Addis Ababa were selected randomly. Data were collected on relationship satisfaction and conflict resolution behavior of couples. The constructs were measured by Relationship Assessment Scale (RAS, Hendrick, 1988 and Rahim Organizational Conflict Inventory-II (ROCI-II, Rahim, 1983). Pearson correlation and standard multiple regressions were run to check association and prediction among variables under study respectively. Result: The result confirmed that statistically significant correlation was found between/among most variables/constructs in the study. The standard regression revealed that conflict resolution behavior predicted relationship satisfaction. Particularly integrating, dominating and avoiding conflict type of conflict resolution styles predicted relationship satisfaction individually. Conclusion: It is therefore, possible to conclude that all the conflict resolution style sub scales predicted relationship satisfaction significantly.

Keywords: Conflict Resolution Style, Relationship Satisfaction, Couples

Close relationships are essential to health and well-being. The capacity to form intimate relationship with others is considered as an essential developmental task and a principal feature of effective personality development (Bowlby, 1988; Cassidy, 2001; Loubser, 2007). Consequently, people strive to have successful intimate (couple) relationships, yet for centuries,

\footnotetext{
${ }^{1} \mathrm{PhD}$, Developmental Psychology, Assistant Professor, Addis Ababa University, Arba Minch, Ethiopia

*Responding Author

(C) 2016 I E Ayenew; licensee IJIP. This is an Open Access Research distributed under the terms of the Creative Commons Attribution License (http://creativecommons.org/licenses/by/2.0), which permits unrestricted use, distribution, and reproduction in any Medium, provided the original work is properly cited.
} 


\section{Association of Conflict Resolution Style and Relationship Satisfaction between Couples}

the exact manner in which to accomplish this has remained an enigma. In fact a great deal is known about the inner working of the couple relationship today than the previous times. Couple relationship is the emotional (eg. cohabitation) or emotional and legal (marriage) commitment between two opposite sex individuals to share emotional and physical intimacy, a variety of tasks and economic resources.

Marriage has long been an important social institution by forming family which occupies a central place in the lives of men, women, and children around the world. The fact that family is "a source of support, and sometimes an obstacle, to individual and collective achievements; $a$ unit of economic production and consumption; an emotional haven that can sometimes be a source of emotional strain; and a vehicle for extending care giving and culture across the generations, for better and for worse ( Laura, Lippman and Wilcox, 2013).

Nevertheless, research finding indicated that being involved in a relationship in terms of marriage, even in cohabitation improves the well-being of both men and women in the family (McKeown, 2001). Some of the most informing evidences on the importance of marriage emerged from studies of the factors, which contribute to individual well-being. For instance in the United States of America, the general social survey has measured well-being over a period of 25 years (1972-1998) using the following question: "Taken all together, how would you say things are these days? Are you very happy, pretty happy, or not too happy” (Fowers, 1998)? In Britain, a broadly similar question was used in Eurobarometer surveys to measure well-being over the same period which states "on the whole, are you very satisfied, fairly satisfied, not very satisfied, or not at all satisfied, with the life you lead” (Theodossiou, 1998). In both countries, controlling for a number of socio-economic variables, being married (rather than single, separated, widowed or even remarried) had a more powerful impact on well-being than either income or employment. Similar results have been found in other countries, expressing marriage positively being happier than others (Sweeney, 1998).

Moreover, there is a striking consistency in the results of the different studies. A 17-nation study of the factors associated with feeling happy found that the three predictors of happiness, in their order of importance, were feeling healthy, feeling financially secure and being married (Stack and Eshleman, 1998). In the case of marriage, this study reported that married persons have a significantly higher level of happiness than persons who were not married, even when all key socio-economic variables are controlled.

Marriage is the privileged institute in Africa too. In fact Africa is one continent with several worlds. Marriage in Africa has been commonly described as early and universal and this situation has partially been blamed for the persistence of high fertility in the region. In Africa, marriage patterns vary across and within countries among different ethnic groups. Such variations could be due to both cultural and socio-economic factors. Although it varies, the major aspect of marriage is to maintain and continue personal and social well being. A study 


\section{Association of Conflict Resolution Style and Relationship Satisfaction between Couples}

(Tiliouine, 2009) conducted in Algeria on health and subjective well being revealed that there is an association between marriage and personal well being.

Marriage in Ethiopia is one of the respected social phenomena as a rite of passage and forming well being that many people are going to engage. For instance, the result of the 2007 census (SCA, 2007) showed that 50 percent of the population was married from age of ten and only three percent divorced. However, it is important to remember that the simple presence of a spouse is not necessarily protective. A troubled marriage is itself a prime source of stress and dissatisfaction while simultaneously limiting the partner's ability to seek support in other relationships. One of the prime causes that make a relationship in trouble is conflict resolution approach.

Researchers argue that conflict only results in relationship dissatisfaction and breakdown if couples are ill equipped to solve or dissolve it (Markman, Stanley and Blumberg, 1994; Gottman, 1997; Hanzal and Segrin, 2011). Markman et al., (2011) have developed and researched this idea and summarized, contrary to popular belief, it is not how much you love each other that can best predict the future of your relationship, but how conflicts and disagreements are handled. Unfortunately, conflict is inevitable and cannot be avoided. So if someone wants to have a satisfying marriage, he/she would better learn to fight right (Markman et al., 1994). The idea was further strengthened by John Gottman in his popular saying, "Through my long years of research, I come up with a conclusion that marriage resulted in divorce due to couple's failure to resolve conflict that is inevitable in a relationship" (Gottman, 1997, pp.103).

However, research works done on the role of conflict resolution styles on relationship satisfaction have been disregarded. Although unanimously disliked, conflict resolution styles functions as an opportunity to resolve differences between relational partners which lead to relationship satisfaction (Shi, 2003; Plessis, 2006; Feeny, 2008). That is the basic reasons for the present researcher to focus on the effect of conflict resolution styles on relationship satisfaction.

\section{RESEARCH METHODS AND MATERIAL}

\section{Study Area}

The study area is Addis Ababa and was selected purposively. Addis Ababa represents a heterogeneous population in many social characteristics. The study included is heterosexual couples. Addis Ababa is the capital city of Ethiopia established in 1886. It is geographically located at the heart of the country. It accommodates about $35 \%$ of the total urban population in Ethiopia. Addis Ababa City has a total population of 2,738,248 with a growth rate of 2.1 percent per annum (additional 57,503 people per year), where around 52\% of the populations composed of children and adolescents below age 25. From the total population, 48 percent are males and 52 percent are females (CSA, 2007). There is a seven year gap and recently the total population of 


\section{Association of Conflict Resolution Style and Relationship Satisfaction between Couples}

Ethiopia assumed to reach to 90 million and the population of Addis Ababa also has increased. However, official documents are not yet revealed.

Addis Ababa City is divided into 10 Sub-cities; again the Sub-cities are divided in to 99 Kebeles. There is a disparity in Sub-city population distribution which shows uneven distribution. The whole population is urban dweller. The majority of the city population lives in Kolfe Keranyo (15.6\%) and Yeka (12.6\%), while Arada (7.7\%) and Akaki Kality Sub City (6.7\%) have the smallest share from the city's total population.

\section{Research Design and Population}

A no experimental explanatory design was used to investigate the question of interest. The design is no experimental because there is no manipulation of independent variables, which were investigated in the study. In this design, the levels or categories of the independent variables were already defined or classified so that the researcher has no opportunity to manipulate or randomly assign individuals to certain groups. It is explanatory since the objective of the study is to test hypotheses derived from a given theoretical orientation. Moreover, cross-sectional method was used to collect data at a time to make comparisons across different categories of respondents. The target population of this study was adult heterosexual couples while the study population was adult heterosexual couples in Addis Ababa Administrative City. The study site overview and sampling techniques are presented hereafter.

\section{Sample Size Determination and Sampling Procedure}

To determine the size of population having the attribute that is couple relationship (married) Central Statistics Authority (CSA, 2007), 50\% was used. Therefore, for s ingle proportion population, to derive the sample size in relation to the total populations sizes the proportional distribution of the attributes taken in to consideration i.e. $50 \%$. Then at 95\% confidence interval and +/- $5 \%$ significance level the sample size calculated became 384. Thus, 384 married (cohabited) from a total of 384 households were included in the study.

$$
\begin{gathered}
\mathrm{n}=\left\{\mathrm{Z}^{2} \mathrm{x} \frac{p x q}{\mathrm{~d} 2}\right\} \\
\text { Where: } \mathrm{n}=\text { sample size } \\
\mathrm{z}=\text { Confidence interval (95\%) } \\
\mathrm{p}=\text { Expected prevalence (as fraction of } 1 \text { ) } \\
\mathrm{q}=1-\mathrm{p} \text { (expected non-prevalence) } \\
\mathrm{d}=\text { relative desired precision }
\end{gathered}
$$

Yeka sub city was taken purposely among the 10 Woredas in Yeka sub city, three were selected using simple random sampling method. To reach households which are the analysis unit of the study, systematic simple random sampling was used based on the sampling frame obtained from Keble household registration database. 


\section{Association of Conflict Resolution Style and Relationship Satisfaction between Couples}

\section{Data Collection Tools and Process}

The researcher used a demographic questionnaire and two structured questionnaires. The demographic questionnaire contains nine items that elicits personal information from each respondent. The structured questionnaire includes: Experiences in Close Relationships-Revised (ECR-R), to collect data on adult attachment experience and Rahim Organizational Conflict Inventory-II (ROCI-II), to make inventory on how respondents resolve conflicts with their partners.

\section{Conflict resolution styles}

Rahim Conflict Resolution Inventory was used to collect data regarding conflict resolution styles of couples. The instrument contains 28 items and five styles of handling conflict in a 5-point Likert scale. The conflict handling styles are; integrating, obliging, dominating, compromising and avoiding conflict. Higher score in integrating and compromising indicates functional conflict resolution style while higher score in obliging, dominating and avoiding conflict indicates dysfunctional conflict resolution style.

\section{Relationship Satisfaction}

Relationship Assessment Scale (Hendrick, 1988), was used to asses intimate relationships including dating, cohabiting and engaged couples. This unifactorial Relationship Assessment Scale (RAS; Hendrick, 1988) assesses satisfaction in romantic relationships. The 7-item RAS contains questions about satisfaction with one's partner, the relationship as a whole and the extent to which needs are met within the relationship. The RAS employs a 5-point Likert scale ranging from low satisfaction to high satisfaction and yields one total RAS score ranging from 7 to 35; higher scores correspond with greater relationship satisfaction.

\section{Open-ended Questions}

To capture the personal opinion and to answer some research questions that could not be covered by the structured questionnaire or to supplement it, some open-ended items were prepared. These open-ended questions were focused on the factors that contribute to relationship conflict and the impact of conflict resolution styles on couple relationship satisfaction. The intention was to compensate the drawback of structured questionnaire by letting respondents to express their personal opinion, attitude and experience freely in their own words.

\section{Methods of Data Analysis}

Prior to conducting the analyses, the data collected were examined for accuracy of data entry, normality, missing values and collinearity. The data were found to have dependable data, normal distribution, no significant missing values and the scales and subscales which were considered as independent variables were not collinear. Person correlation was run to examine the relationship adult attachment and conflict resolution style. Multiple regressions were run with attachment anxiety and attachment avoidance as the independent variables and conflict resolution styles (integrating, compromising, obliging, dominating and avoiding conflict) as dependent variables. 
Moreover, MANOVA was used to compare the conflict resolution styles of male and female research participants.

\section{RESULTS}

Demographic Data (Categorical) (n=306)

\begin{tabular}{|c|c|c|}
\hline Demographic Variable & Frequency & Valid Percent \\
\hline \multicolumn{3}{|l|}{ 1. Sex } \\
\hline Female & 157 & 51.3 \\
\hline Male & 149 & 48.7 \\
\hline Total & 306 & 100 \\
\hline \multicolumn{3}{|l|}{ 2. Age } \\
\hline 20- 25 years old & 21 & 6.9 \\
\hline 26-40 years old & 218 & 71.9 \\
\hline 41-60 years old & 56 & 18.5 \\
\hline$>60$ years old & 8 & 2.6 \\
\hline Total & 303 & 100 \\
\hline \multicolumn{3}{|l|}{ 3. Marital status } \\
\hline Married & 245 & 81.1 \\
\hline Cohabited & 19 & 6.3 \\
\hline Divorced & 7 & 2.3 \\
\hline Single & 30 & 9.9 \\
\hline Total & 302 & 100 \\
\hline \multicolumn{3}{|l|}{ 4. Duration in relationship } \\
\hline$<$ a year & 6 & 2.2 \\
\hline $1-5$ years & 105 & 39.2 \\
\hline 6-10 years & 65 & 24.3 \\
\hline$>10$ years & 92 & 34.3 \\
\hline Total & 268 & 100 \\
\hline
\end{tabular}

The majority (71.9 \%) of the respondents were in the age category of 26 to 40 years old, which is relatively in early adulthood category of chronological age. The other 56 (18.5\%) fall in the age category of 41-60 years old which is congruent to the chronological age of middle adulthood. Therefore, most, $90.2 \%$ of the respondents were in early and middle adulthood chronological age. The majority, 245 (81.1\%) of the respondents reported that they are married, 30 (9.8\%) reported that they are single, 19 (6.2\%). Thirty nine percent of the respondents reported that they are in a relationship for one to five years, while 92 (34.2\%) of the respondents reported that they are in a relationship for more than 10 years. 
Level of Education and Income $(n=306)$

\begin{tabular}{|c|l|l|}
\hline Variables & Frequency & Valid Percent \\
\hline 1. Education Level & & \\
\hline Below high school & 9 & 3.0 \\
\hline High school complete & 66 & 21.9 \\
\hline Diploma/Certificate holders & 108 & 35.9 \\
\hline First degree holders & 86 & 28.6 \\
\hline Above first degree holders & 32 & 10.6 \\
\hline Total & 301 & 100 \\
\hline 2. Monthly Income & & \\
\hline No Income & 10 & 3.7 \\
\hline 500-1000 birr & 15 & 5.6 \\
\hline 1001-1500 birr & 30 & 11.2 \\
\hline 1501-2000 birr & 20 & 7.4 \\
\hline 2001-2500 birr & 32 & 11.9 \\
\hline Total & 162 & 60.2 \\
\hline & 269 & 100 \\
\hline
\end{tabular}

Approximately 36\% of the respondents were diploma/certificate holders, while $28.6 \%$ and 21.9 \% were first degree holders and those who did finish high school (grade 10/12) respectively. Around 11\% respondents hold their second degree and above. This implies that more than 75.5\% of the respondents in the present study are trained in different fields with diploma and above. Moreover, $60.2 \%$ of the respondents earned more than 2500 Ethiopian birr per month while $11.9 \%$ of the respondents reported of getting 2001-2500 per month (Table 5). This implies that $72 \%$ of the research participants earned more than 2000 birr per month.

\section{Correlation between Demographic, Independent and Dependent Variables}

Pearson correlations were run between the demographic variables of age, education level, monthly income and relationship duration with the independent and dependent variables as follows in Table 6.

Table 6: Pearson Correlation between the Demographic Variables and the Independent and Dependent Variables

\begin{tabular}{|l|l|l|l|l|l|l|}
\hline & IN & OB & DO & AC & CO & RS \\
\hline Age & -.067 & .020 & 0.039 & .039 & .086 & -.010 \\
\hline Level of Education & .052 & .058 & -.075 & -057 & -.038 & -.017 \\
\hline Monthly Income & $.116^{*}$ & .051 & $-.168^{* *}$ & $-.177^{* *}$ & $.135^{*}$ & $.208^{* *}$ \\
\hline Relationship duration & -.069 & .000 & -.014 & -.014 & .097 & .043 \\
\hline
\end{tabular}

Two-tailed significance: ${ }^{*} p<0.01 ; * * p<0.001$

Note: IN=Integrating, $\mathbf{O B}=$ Obliging $\mathbf{D O}=$ Dominating, $\mathbf{A C}=$ Avoiding Conflict, $\mathbf{C O}=$ Compromising, $\boldsymbol{R S}=$ Relationship Satisfaction .

Age and relationship duration were not statistically significant association with any of the independent and dependent variables included in the study. Moreover, sex has no statistically significant relationship with any of the variables included except conflict resolution styles 
(Integrating and dominating). There is statistically significant positive association between sex and integrating style of conflict resolution styles $(\mathrm{r}=.184, \mathrm{p}<.01)$, while sex has statistically significant negative association with dominating style of conflict resolution styles ( $\mathrm{r}=-.191$, $\mathrm{p}<.01$ ). Level of education has no statistically significant association with couple's relationship satisfaction. Income level and conflict resolution styles have statistically significant association. Income had statistically significant positive association with integrating type of conflict resolution styles $(\mathrm{r}=.116, \mathrm{p}<.01)$ and compromising type of conflict resolution styles $(\mathrm{r}=.135$, $\mathrm{p}<.01$ ). Income also had statistically significant negative association with dominating and avoiding conflict type of conflict resolution styles $(\mathrm{r}=-.168, \mathrm{p}<.001$ and $\mathrm{r}=-.177, \mathrm{p}<.001$ ) respectively. Unlike education level, income has statistically significant positive association with relationship satisfaction $(\mathrm{r}=.208, \mathrm{p}<.001)$. Therefore, the analysis shows that income has better association with the dependent and independent variables than any other demographic factors.

\section{Factors Contributing to Couples' Conflict}

Open-ended question was forwarded for selected respondents (as key informants) to get relevant information from couples as indicated in population. There are a number of factors stated by research participants that contribute for conflict between couples. To name: income, lack of transparency, unfaithfulness, communication problem, other's interference, unfaithfulness, alcohol and drug use, not respecting each other, male dominance behavior, decrease time spent together, sexual dissatisfaction, age difference, income differences, difference in opinion, cultural differences, religion, ethnicity, education level, lies, lack of deep love, not tolerating each other, inability to control emotion, comparing ones' marriage with others, lack of forgiveness, male dominance behavior (lack of egalitarianism), jealousy, unrealistic expectations and lack of self-confidence, were some of the factors contributed to couple conflict that has been mentioned by many respondents. However, the following table summarizes the most significant factors.

\section{Frequency and Percentage of Factors Contributing to Couple Conflict $(n=61)$}

\begin{tabular}{|l|l|c|l|}
\hline S. No & Variables & Frequency & Percent \\
\hline 1 & Income & 28 & 45.90 \\
\hline 2 & Lack of transparency & 27 & 44.26 \\
\hline 3 & Unfaithfulness & 23 & 37.70 \\
\hline 4 & Problems of communication & 21 & 34.42 \\
\hline 5 & Others' interferences & 21 & 34.42 \\
\hline 6 & Male dominance behavior & 17 & 27.87 \\
\hline 7 & Sexual Problems & 11 & 18.03 \\
\hline 8 & Not respecting each other & 9 & 7.74 \\
\hline 9 & Alcohol and drug use & 9 & 14.75 \\
\hline 10 & $\begin{array}{l}\text { Differences (Religion, ethnicity, age, beauty, } \\
\text { education level) }\end{array}$ & 19 & 34.15 \\
\hline 11 & $\begin{array}{l}\text { Others (ignorance, lies, jealousy, not tolerating each } \\
\text { other, comparing ones marriage with others, not } \\
\text { knowing each other well before marriage) }\end{array}$ & 30 & 49.18 \\
\hline
\end{tabular}


Bivariate Correlation of the Variables of Interest

\begin{tabular}{|l|l|l|l|l|l|l|}
\hline Measures & $\mathbf{1}$ & $\mathbf{2}$ & $\mathbf{3}$ & $\mathbf{4}$ & $\mathbf{5}$ & $\mathbf{6}$ \\
\hline IN & 1 & & & & & \\
\hline CO & $.55^{* *}$ & 1 & & & & \\
\hline OB & $.46^{* *}$ & $.52^{* *}$ & 1 & & & \\
\hline DO & $-.30^{* *}$ & -.07 & -.07 & 1 & & \\
\hline AC & .05 & $.23^{* *}$ & $.29^{* *}$ & $.17^{* *}$ & 1 & \\
\hline RAS & $.35^{* *}$ & $.25^{* *}$ & $.28^{* *}$ & $-.20^{* *}$ & -.11 & 1 \\
\hline
\end{tabular}

Correlations significant at the $p<0.01$ level are indicated by $*$ and correlations significant at the $p<0.001$ level are indicated by **

Note: IN=Integrating, $\quad \boldsymbol{O B}=$ Obliging $\quad \boldsymbol{D O}=$ Dominating, $\boldsymbol{A C}=$ Avoiding $\quad$ Conflict, $\mathbf{C O}=$ Compromising,$\quad \boldsymbol{R A S}=$ Relationship Satisfaction.

Conflict resolution styles subscales had statistically significant association with relationship satisfaction. Therefore, relationship satisfaction is positively associated with integrating $(\mathrm{r}=.35$, $\mathrm{p}<.001)$, compromising $(\mathrm{r}=.25, \mathrm{p}<.001)$, and obliging $(\mathrm{r}=.28, \mathrm{p}<.001)$ and negatively associated with dominating $(\mathrm{r}=-.20, \mathrm{p}<.001)$.

\section{Regressions of Conflict Resolution Styles on Relationship Satisfaction}

\begin{tabular}{|l|l|l|l|l|l|}
\hline & Beta & t & p & F & R-Square \\
\hline DV: Relationship satisfaction & & & & & \\
IV: Integrating & .212 & 2.899 & .004 & & \\
Compromising & .078 & 1.111 & .267 & 11.915 & $.178 * *$ \\
Obliging & .179 & 2.639 & .009 & & \\
Dominating & -.064 & -1.077 & .283 & & \\
Avoiding conflict & -193 & -3.275 & .001 & & \\
\hline
\end{tabular}

Note: ${ }^{* *} p<0.001$

In this regression analysis, integrating, obliging and avoiding conflict subscales of conflict resolution styles contributed significantly for the prediction of relationship satisfaction. This implies higher score in integrating style of conflict resolution styles was associated with higher level of relationship satisfaction. Higher levels of obliging type of conflict resolution associated with higher level of relationship satisfaction. Eventually, higher level of avoiding conflict style of conflict resolution styles associated with lower level of relationship satisfaction. All the subscales of conflict resolution styles contributed $17.8 \%$ of the variance of relationship satisfaction. Overall, hypothesis two was confirmed. Conflict resolution styles is strong predictor of relationship satisfaction. 
Mean Scores and Standard Deviation Measures of Conflict resolution styles Sub-scales as a Function of Sex

\begin{tabular}{|l|l|l|l|l|l|l|l|l|l|l|l|}
\hline & \multicolumn{3}{|l}{ Integrating } & \multicolumn{2}{l|}{ Compromising } & \multicolumn{2}{l|}{ Obliging } & \multicolumn{2}{l|}{ Dominating } & \multicolumn{2}{l|}{$\begin{array}{l}\text { Avoiding } \\
\text { conflict }\end{array}$} \\
\hline Group & $\mathrm{M}$ & $\mathrm{SD}$ & $\mathrm{M}$ & $\mathrm{SD}$ & $\mathrm{M}$ & $\mathrm{SD}$ & $\mathrm{M}$ & $\mathrm{SD}$ & $\mathrm{M}$ & SD \\
\hline Female & 27.92 & 5.05 & 14.46 & 2.85 & 22.24 & 3.63 & 12.19 & 3.45 & 19.82 & 4.23 \\
\hline Male & 29.64 & 4.26 & 15.09 & 2.64 & 22.50 & 4.12 & 10.74 & 3.50 & 19.72 & 3.82 \\
\hline
\end{tabular}

It appears that male respondents achieved higher mean score in integrating conflict resolution styles $(M=29.64, S D=4.26)$ than female respondents $(M=27.92, S D=5.05)$. In Dominating type of conflict resolution styles, female respondents achieved higher mean score in dominating conflict resolution styles $(\mathrm{M}=12.19, \mathrm{SD}=3.45)$ than male respondents $(\mathrm{M}=10.74, \mathrm{SD}=3.50)$. These indicate that statistically significant sex impacts were observed for integrating and dominating conflict resolution styles but not in obliging, avoiding conflict and compromising conflict resolution styles.

\section{DISCUSSION}

Education lets couples tolerate conflict happen in their relationship and give time for discussion and reach in to consensus. However, level of education had no statistically significant association with conflict resolution styles and relationship satisfaction. Based on the results of this study level of education does not intervene with conflict resolution styles and relationship satisfaction. in the contrary, level of education and relationship satisfaction had negative association though it was weak (insignificant). This implies as education level increases, the satisfaction that couples derive from their relationship tends to fall. This seems something unexpected and the possible explanation may be individuals need and expectation became higher when one is educated more.

Income had statistically significant positive association with functional conflict approaches and relationship satisfaction. Couples who earn better income have the likelihood of resolving conflicts happened between themselves using integrating and compromising type of conflict resolution styles. Therefore, level of income has positive contribution on couple's conflict resolution styles. The level of income has also statistically significant positive association with relationship satisfaction. This implies couples who earn better income have the likelihood to derive better relationship satisfaction or level of income has reasonable influence on couple's relationship satisfaction.

Previous studies show association between conflict resolution styles and relationship satisfaction (Bumpass, 2002; Collins et al., 2006). In the present study statistically significant positive association between relationship satisfaction and integrating, compromising and obliging type of conflict resolution styles were found. The direct relationship between relationship satisfaction and integrating and compromising was expected and supported by previous studies (eg. Plessis, 


\section{Association of Conflict Resolution Style and Relationship Satisfaction between Couples}

2006). It implies as couples exercised more of functional conflict approach (integrating and compromising), their relationship strengthens and resulted in relationship satisfaction. However, the direct and statistically significant positive relationship between relationship satisfaction and obliging was different from the assumptions made. Obliging is considered as low self-concern and high-concern with others, which resulted in dysfunctional conflict approach (Rahim, 1983; Defrain and Olsen, 2003). Therefore, inverse association was expected and such relationship got further elaboration later. Relationship satisfaction had negative association with dominating type of conflict resolution, in which it deteriorates couples communication and result in low relationship satisfaction.

\section{The Causes of Couple Conflict}

Researchers indicated that different factors contribute to conflict in couple relationship. The present researcher also wanted to find out the actual and potential factors that contribute for couple's conflict in the present sample. Respondents listed and prioritized the factors that lead to couple conflict. Money (income) was the first priority listed that leads couple to conflict. Income earned was raised as a source of the problem in terms of its source (husband or wife earning), imbalance of the husband and wife monthly earning and the management problem of either of them were forwarded as the reason for income as a cause of couple conflict. Moreover, it was stated that money as a source of conflict not only in terms of its shortage but also sometimes excess money may become a source of conflict. Therefore, most disagreements between couples are related to money and this was true in previous research reports too (Habtamu, 1998; Wilson and Daly, 2001; Guerrero et al., 2001).

Lack of transparency was the second factor that has been prioritized by respondents. They were complaining about lack of transparency between couples. Either of them or both lack the experience to share what they are going to do or what they did. Actually this problem might have resulted from or as a result of lack of communication and unfaithfulness. In one way or another, these factors influence each other. If a partner is unfaithful, he/she could hardly be transparent which in turn impair open communication between couples. Unfaithfulness brings jealousy, and lack of transparency which possibly resulted in impaired communication and invites them to spend even their free time separately. Previous research reports show lack of communication, lack of transparency, unfaithfulness, jealousy (suspicious on adultery), not spending enough time together and engaging in emotional or sexual infidelity were the major contributing factors for couple’s conflict (Habtamu, 1998; Cinamon, 2006).

The other most important contributing factor that was observed from the present respondents' response was interference. Just equal to lack of communication, others' interferences were reported as a serious problem that contributes to couples conflict. Mother, father, brothers, sisters or friends from either side interfere in couple's relationship. Especially female respondents were strained on the interference of a husband's mother or sister in couple relationship. 


\section{Association of Conflict Resolution Style and Relationship Satisfaction between Couples}

Moreover, research participants pointed out that differences between couples like religion, education level, ethnicity and age also contributed to couple conflict. Research participant's explained that at the start of romantic love, the religion and ethnicity differences were not explicitly observed and discussed as an issue. However, the problem begins to be noticed when couples start to live together and have a child or children. Couples start to forward ideas, imagine thoughts and observe opinion differences that have never been raised earlier as an issue. They also explained that it is unlikely to genuinely discuss and reach in to an agreement on matters like religion and ethnicity. On these issues as respondents explained, they take their own side and strived to protect themselves in one way or another. Even couples start to believe that such ideas are impervious and could never be presented on the discussion table. It widens the difference between couples and less likely to be transparent. Lack of transparency hinders proper communication and dysfunctional conflict approach (dominating, avoiding conflict and obliging) would follow. Eventually the common things that bind them deteriorate and common ideas decrease and the emotional bond that ties them starts to loosen. Actually studies were not available in this issue and the present researcher could not support with empirical evidence done by other researchers.

\section{Conflict Resolution Styles and Relationship Satisfaction}

Conflict resolution styles has predictive impact on relationship satisfaction. Previous research reports also indicated that couples engage in and try to resolve conflicts is one of the major indicators of relationship functioning (Bumpass, 2002; Collins et al., 2006). Explicitly, functional conflict approach will result in higher relationship satisfaction and dysfunctional conflict approach will result in lower relationship satisfaction.

In the present research integrating, obliging and avoiding conflict subscales of conflict resolution styles contributed significantly for the prediction of relationship satisfaction. Integrating is a functional conflict approach which predicts directly the relationship satisfaction. Obliging and avoiding conflict also predict individually relationship satisfaction as they are dysfunctional conflict approach. This implies higher score in integrating style of conflict resolution styles was associated with higher score in relationship satisfaction. Higher score in obliging type of conflict resolution styles associated with higher score in relationship satisfaction. Eventually, higher score in avoiding conflict style of conflict resolution styles is associated with lower core in relationship satisfaction. Therefore, how both partners solve problems and cope with conflict not only predicts whether a partnership will remain intact or break up, but also influences whether a current relationship experienced is satisfactory or not (Gottman and Driver, 2005).

There has been a considerable amount of research showing that romantic relationships have various correlates. Dysfunctional conflict approaches, such as dominating (personal attacks and losing control) and avoiding (refusing to discuss the issue further and tuning the other partner out), have been found to be negatively related to relationship satisfaction, whereas the functional conflict approaches (integrating and compromising) supports a satisfied relationship partnership (Kurdek, 1995; Marchand, 2004). However, findings regarding the conflict resolution styles of 


\section{Association of Conflict Resolution Style and Relationship Satisfaction between Couples}

obliging (giving in and not defending one's position) were not as consistent (Kurdek, 1994) and obliging was the one particular conflict resolution style least likely to be related to relationship outcomes. However, obliging type of conflict resolution styles had direct predictive impact on relationship satisfaction in the present research result. This might be due to the consistent insisting of one's couple to calm conflict might result in agreement which leads to satisfaction.

\section{Gender and Conflict Resolution Styles}

Comparison on conflict resolution style of men and women were done using MANOVA. Gender differences were found in integrating and dominating type of conflict resolution styles. However, there was no significant mean difference between male and female respondents in compromising, avoiding conflict and obliging type of conflict resolution styles. This implies females were practicing dominant type of conflict resolution styles. Society has defined femininity as being soft, weak, considerate, and expects females to be problems fixers in a relationship and most of the time obliging type of conflict resolution styles. To many females, it is their duty to approach their male partners for conflict resolution. However, being dominating could be one consequence of anxiously attached females. As individuals become more anxious, they start to be over activated and tried to dominate the situation when conflict arises. This might also bring the behavior of being dominant type of conflict resolution styles for female respondents in this research.

A statistically significant mean score difference between male and female participants were found in integrative type of conflict resolution styles. Previous research reports did not indicated any kind of gender differences on integrating type of conflict resolution styles. However, in this research statistically significant mean score differences between male and female participants were found in integrating type of conflict resolution styles. The mean score of males were higher than the mean score of females with regard to integrating type of conflict resolution styles. It means, male participants involve more in integrating type of conflict resolution styles than female participants. While being integrative is a positive quality in relationship satisfaction, the fact that either of partners should not be more concerned with being integrative, as it handicaps relationships and reduces relationship satisfaction.

The observation that males in this sample in general are more likely to pull in to agreements and are more willing to participate in conflict resolution makes it easy to see that the combination of integrating males and dominating females could soon lead to pursue effective interaction pattern that is predictive of relationship satisfaction.

\section{CONCLUSIONS AND IMPLICATIONS}

The present study examined effect of conflict resolution behavior on couple relationship satisfaction. The present researcher specifically addressed two approaches of conflict approaches, functional and dysfunctional and their association relationship satisfaction. Based on the discussion the following conclusions are made. 


\section{Association of Conflict Resolution Style and Relationship Satisfaction between Couples}

1. The level of education had no significant relationship with conflict resolution styles and relationship satisfaction. Therefore, it can be concluded that the level of education could not guarantee for having relationship satisfaction and functional conflict resolution styles.

2. Income had significant impact in conflict resolution styles and relationship satisfaction. Therefore, it is possible to conclude that level of income is one of the factors that increase enhance functional conflict approach and increase couples' relationship satisfaction.

3. It was found that, there are various factors that contribute to couples' conflict. However, the major factors stated by respondents and summarized by the present researcher were ranked as income, lack of transparency, lack of communication, unfaithfulness, jealousy (committing adultery), not spending enough time together and engaging in emotional or sexual infidelity were the major contributing factors.

4. Conflict resolution styles had significant predictive power on relationship satisfaction. Therefore, the analysis explicitly shows that integrating, obliging and avoiding conflict type of conflict resolution styles predicts relationship satisfaction between couples.

\section{Implications}

The findings of the present study help to explain people's behavior for intervention. Some people have difficulties in starting and continuing adult intimate relationship and some others even seem to lack the wish or competence to become deeply involved with others. Moreover, it is observed that though couples love each other very well, they go through hard times with uncomplicated problems due to lack of effective conflict resolution styles.

Because of the importance of conflict resolution styles, it is helpful for marriage /couple/ therapists to address conflict resolution behavior and highlight how they are displayed in romantic relationships. The counselor should understand the conflict approach that couples use in their conversations. By listening and observing their conversational emotions the therapist can understand the approach of conflict that couples are using. Therefore, the therapist can teach and counsel clients on how their conversation and emotion affects to reach in to common consensus during communication. Therefore, teaching and practicing more effective conflict resolution styles may assist in building a secure base for each member of the partner. The therapist needs to pay special attention to the more delicate characteristics of avoidant behaviors, and highlight their dynamics and effects when necessary.

Research reports indicate that, on average, children who grow up in families with both their biological parents in a low-conflict marriage are better off in a number of ways than children who grow up in single, step or cohabiting-parent households. However, in individual situations, children became better off depending on whether the marriage is "healthy" and stable. Marriage is a proxy for other parental characteristics associated with relationship stability and positive child outcomes. 


\section{REFERENCES}

Bowlby, J. (1988). A secure base. New York: Basic Books.

Bumpass, L. (2002). Family-related attitudes, couple relationship and union stability. In R. Lesthaeghe (Ed.), Meaning and choice: Value orientation and life cycle decisions. The Hague, Netherlands: Netherlands Interdisciplinary Demographic Institute.

Cassidy, J. (2001). Truth, lies and intimacy: An attachment perspective. Attachment and Human Development, 3, 121-155.

Cinamon, Rachel G. (2006). Anticipated work-family conflict: effects of gender, self-efficacy and family background. Career Development Quarterly, 54(6), 202-216.

CSA. (2007). Summary Report of the census of Ethiopia, Addis Ababa Press.

Gottman, J. M. and Driver, J. (2005). Dysfunctional marital conflict and everyday marital interaction. Journal of Divorce and Remarriage, 43, 63-77.

Gottman, J., (1997). Why Marriages Succeed or Fail ... And How You Can Make Yours Last, New York: A Fireside Book.

Guerrero, Laura K., Andersen, P. A. and Afifi, A. (2001). Close Encounters: Communicating in Close Relationships. Mountain View, CA: Mayfield Publishing Company.

Habtamu Wondimu (1998). Conflict Resolution in the families of nine ethnic groups in Ethiopia. The Ethiopian journal of Education, 19, 19-40.

Hanzal, A. and Segrin, C. (2011). The role of in mediating the relationship between enduring vulnerabilities and marital quality. Journal of Family Communication, 9, 150-169

Kurdek, L. A. (1995). in gay, lesbian, heterosexual nonparent, and heterosexual parent couples. Journal of Marriage and the Family, 56, 705-722.

Kurdek, L. A. (1994). Areas of conflict of gay, lesbian, and heterosexual couples: What couples argue about influences relationship satisfaction? Journal of Marriage and Family, 56: 923934

Laura H., Lippman and Bradford W. (2013). World family map. Mapping family change and child well-being outcomes. An International Report from.

Loubser, J. (2007). Attachment theory and adult intimate relationships. Master thesis,

Marchand, J. F. (2004). Husbands and wives marital quality: The role of adult attachment orientations, depressive symptoms and conflict resolution styless. Attachment and Human Development, 6, 99-112.

Markman, H. (1991). Constructive marital conflict is not an oxymoron. Behavioral Assessment, 13, 83-96.

Markman, H., Stanley, S. and Blumberg, S., (1994). Fighting for Your Marriage. San Francisco: Jossey-Bass.

McKeown, K. ( 2001). Fathers and Families: Research and Reflection on Key Questions, December, Dublin: Department of Health and Children.

Olsen, D. H. and DeFrain, J. (2003). Marriages and Families: Intimacy, Diversity and Strengths ( $4^{\text {th }}$ Ed.).McGraw-Hill Education.

Parkes, C. M. (2006). Love and loss: The roots of grief and its complications. New York: Taylor. 


\section{Association of Conflict Resolution Style and Relationship Satisfaction between Couples}

Plessis, K. (2006). Attachment and conflict in close relationships: The association of attachment with , conflict beliefs, communication accuracy and relationship satisfaction. Dissertation work, Massey University: Albany.

Population Affairs Coordination Sub process Finance and Economic Development Bureau (2010). Atlas of Key Demographic and Socio Economic Indicators, Addis Ababa.

Rahim, F. (1983). A measure of styles of handling interpersonal conflict. Academy of Management Journal 26, 368-376..

Stack, S. and Eshleman, J.R., (1998). "Marital Status and Happiness: A 17-Nation Study". Journal of Marriage and the Family, Volume 60, 527-536.

Sweeny, J., (2001). Why Hold a Job? The Labor Market Choice of the Low Skilled, Ph.D. Thesis, Number 123, Katholieke Universiteit Leuven.

Theodossiou, I. (1998). The Effects of Low-Pay and Unemployment on Psychological WellBeing: A Logistic Regression Approach, Journal of Health Economics, p. 17.

WHO (2013). Global and regional estimates of violence against women: prevalence and health effects of intimate partner violence and non-partner sexual violence. 